\title{
Potential of siliceous fly ash and silica fume as a substitute for binder in cementitious concretes
}

\author{
Damian Marek Gi1 ${ }^{1, *}$, Grzegorz Ludwik Golewski ${ }^{1}$ \\ ${ }^{1}$ Faculty of Civil Engineering and Architecture, Lublin University of Technology, Nadbystrzycka, 40 str. \\ 20-618 Lublin, Poland
}

\begin{abstract}
Nowadays, concrete constructions are often erected from a material that has been modified with mineral additives or chemical admixtures. Thanks to such modifications, modern and innovative visions of architects and constructors are realizable. Modification of concrete microstructure with mineral additives results in a partial change of its properties as well as physical and mechanical parameters. Ecological and economic reasons are an additional cause of increased interest in the potential use of such additives as fly ash (FA), silica fume (SF), lime powder or granulated blast-furnace slag. The basic physical mechanism of interaction of FA and SF with concrete is primarily to seal the composite microstructure. In the paper a concrete modified with a constant amount of densified silica fume, and a variable percentage amount of siliceous fly ash was analyzed. Concrete samples have been subjected to mechanical and physical tests. Their results allowed to determine the optimal composition of a concrete mix containing the mineral supplements in the context of planned experiments. The use of a combined SF and FA additive as a substitute for a cement binder in a concrete mix allows for an optimal increase in the strength parameters of the concrete, thus not degrading its physical properties. The article presents the characteristics of materials used to make concretes and then analyzes the results of the composites' tests. An in-depth analysis of the results showed the usefulness of silica fumes and siliceous fly ashes as useful raw materials for a concrete production.
\end{abstract}

\section{Introduction}

One of the new directions in the field of concrete technology is the modification of a cementitious binder with a combination of active mineral additives. Therefore, not only two-component [1] but even three- or four-component binders are used to manufacture a concrete mix e.g. [2,3]. Therefore, many research centers carry out studies both on the separate use of silica fume SF e.g. [4,5] and siliceous fly ash FA e.g. [6-11] for concrete, as well as an assessment of the properties of composites, to which a combination of both materials was used e.g. $[12,13]$. Identification of the effects of such a modification, i.e., an assessment of its impact on the properties of concrete microstructure is crucial to design

\footnotetext{
* Corresponding author: d.gil@pollub.pl
} 
the composition of an optimal concrete mix that can be used both in building and industrial construction. It should be noted that, modification of the microstructure of construction materials is also of great importance for other types of composites, e.g. [14-17].

The use of mineral components for concrete such as siliceous fly ash or silica fume contributes to the utilization of huge resources of these products (fly ash production of approx. 1 billion tons/year, silica fume - approx. 1.1 million tons/year) $[18,19]$. Thanks to such measures, the use of cement is also limited, which is associated with the reduction of carbon dioxide emission to the atmosphere, and the reduction of environmental degradation due to the extraction of natural resources used for the production of clinker [20].

\section{Experimental details}

The purpose of the research was to determine the impact of a concrete mix modification with an addition of siliceous fly ash (FA) and densified silica fume (SF) on the physical and mechanical properties of concretes. The scope of research included tests of mechanical parameters such as:

- compressive strength,

- splitting tensile strength, and tests of physical parameters:

- frost resistance,

- water absorption,

- the depth of water penetration under hydrostatic pressure.

The tests were carried out on four types of concretes differing in the amount of FA addition in the following proportions:

- $0 \% \mathrm{FA}+0 \% \mathrm{SF}$ (FA-00+SF-00),

- $0 \% \mathrm{FA}+10 \%$ SF (FA-00+SF-10),

- $10 \% \mathrm{FA}+10 \% \mathrm{SF}(\mathrm{FA}-10+\mathrm{SF}-10)$,

- $20 \% \mathrm{FA}+10 \%$ SF (FA-20+SF-10).

\subsection{Materials used to prepare the samples}

Mixtures were made of: CEM I 32.5R Portland cement from the Ożarów cement plant, natural gravel aggregate with maximum grain size up to $8 \mathrm{~mm}$ from the Rokitno deposit, refined sand from the Niemce deposit, silica fly ash from the Nitrogen Plants "Puławy", densified silica fume from the Ironworks "Laziska", and the Stacheplast 125 plasticizer. The concrete mix recipes are presented in Table 1.

Table 1. Details of concrete mixtures $\left(\mathrm{kg} / \mathrm{m}^{3}\right)$.

\begin{tabular}{|c|c|c|c|c|}
\hline $\begin{array}{l}\text { Component } \\
\text { of the mixture }\end{array}$ & $\begin{array}{c}\text { FA-00+SF- } \\
\mathbf{1 0}\end{array}$ & $\begin{array}{c}\text { FA-00+SF- } \\
\mathbf{1 0}\end{array}$ & $\begin{array}{c}\text { FA-10+SF- } \\
\mathbf{1 0}\end{array}$ & $\begin{array}{c}\text { FA-20+SF- } \\
\mathbf{1 0}\end{array}$ \\
\hline Portland cement CEM I 32.5R & 352 & 317 & 282 & 246 \\
\hline Siliceous fly ash & 0 & 0 & 35 & 70 \\
\hline Silica fume - densified & 0 & 35 & 35 & 35 \\
\hline Water & 141 & 141 & 141 & 141 \\
\hline Sand 0-2 mm & 676 & 676 & 676 & 676 \\
\hline Gravel 2-8 mm & 1205 & 1205 & 1205 & 1205 \\
\hline Plasticizer - Stacheplast 125 & 2 & 2 & 2 & 2 \\
\hline
\end{tabular}


Silica fume is an addition to concrete, which significantly affects its strength parameters and durability. In addition, it seals the composite structure and thus reduces the water absorption of the material. This additive is a waste in the metallurgical industry arising in the production of metallic silicon, ferrosilicon and other silicon alloys as a result of burning of high purity quartz in the continuous-arc-thrust furnaces [21]. Currently in the world, these fumes are the subject of constantly growing interest and use in various concretes. Silica fumes are used for concrete in 3 different forms:

- dry silica fume, not concentrated, with a bulk density up to $350 \mathrm{~kg} / \mathrm{m}^{3}$;

- dry silica fume, densified to $450-700 \mathrm{~kg} / \mathrm{m}^{3}$,

- aqueous siliceous suspension similar to a solid phase colloidal suspension of silica particles and microparticles, and a dispersive phase.

Siliceous fly ash from the Puławy heat and power plant consists mainly of silica $\left(\mathrm{SiO}_{2}\right)$, aluminum oxide $\left(\mathrm{Al}_{2} \mathrm{O}_{3}\right)$, and iron $\left(\mathrm{Fe}_{2} \mathrm{O}_{3}\right)$. The amount of these oxides allows to classify the FA applied in concrete in accordance with the standard [22] to the F class (siliceous ashes).

The X-ray analysis of FA and SF was performed on the PANanalytical X'Pert PRO MPD diffractometer. The FA graph shows that in the phase composition, apart from the glass, there are three crystalline components: quartz, mullite, and hematite (Fig.1.a). The second graph (Fig.1.b) shows the SF analysis, which consists mainly of silica. Other minerals in this additive are silicon carbide and calcium dioxide.

Chemical compositions of the cement used, FA and SF are presented in Table 2.
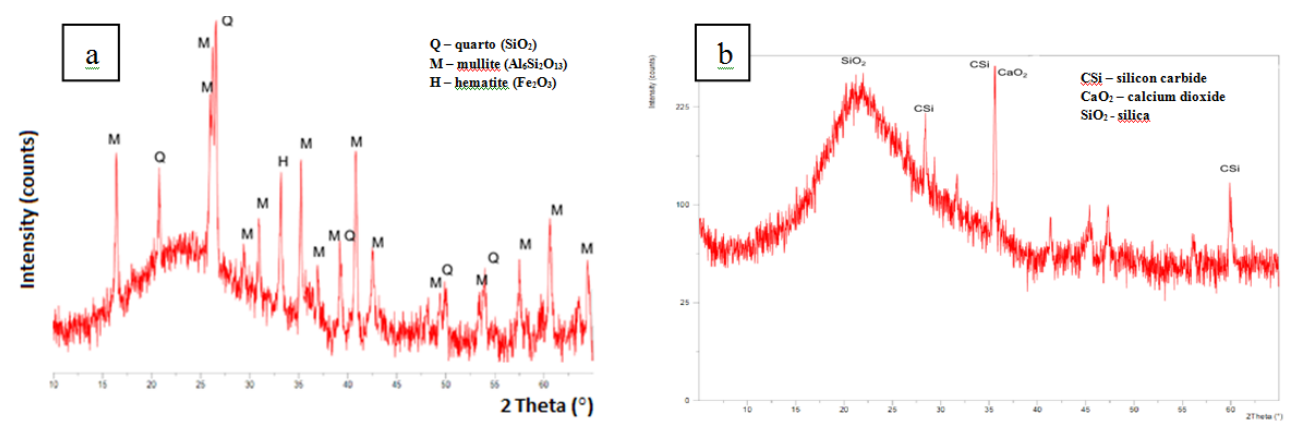

Fig. 1. X-ray diffraction patterns of the (a) FA, (b) SF.

Table 2. Chemical composition of binders [\%].

\begin{tabular}{|c|c|c|c|c|c|c|c|c|c|}
\hline \multicolumn{2}{|c|}{ Components } & $\mathbf{S i O}_{\mathbf{2}}$ & $\mathbf{A l}_{\mathbf{2}} \mathbf{O}_{\mathbf{3}}$ & $\mathbf{F e}_{\mathbf{2}} \mathbf{O}_{\mathbf{3}}$ & $\mathbf{K}_{\mathbf{2}} \mathbf{O}$ & $\mathbf{C a O}$ & $\mathbf{M g O}$ & $\mathbf{S O}_{\mathbf{3}}$ & $\mathbf{L O I}$ \\
\hline \multirow{2}{*}{$\begin{array}{c}\text { Content } \\
{[\% \text { mas. }]}\end{array}$} & $\mathrm{CEM} \mathrm{I} \mathrm{32.5R}$ & 15.00 & 2.78 & 2.72 & 1.21 & 71.06 & 1.38 & 4.56 & 3.64 \\
\cline { 2 - 11 } & $\mathrm{FA}$ & 55.27 & 26.72 & 6.66 & 3.01 & 2.35 & 0.81 & 0.47 & 4.66 \\
\cline { 2 - 11 } & $\mathrm{SF}$ & 91.90 & 0.71 & 2.54 & 1.53 & 0.31 & 1.14 & 0.45 & 3.83 \\
\hline
\end{tabular}

\section{Test results}

\subsection{Compressive and tensile strength of concrete}

The compressive strength test of concrete samples was carried out in the Controls Advatest 9 testing machine (range $0-3000 \mathrm{kN}$ ). The tests were carried out after 28 days of maturation on 6 cubic samples of $150 \mathrm{~mm}$ side from each series. All samples were demoulded one day after they were made. Then for 14 days they were cured in water at a temperature of $18 \pm 2^{\circ} \mathrm{C}$, and in laboratory conditions for the next 14 days. 
The results of compressive and splitting tensile strength tests are shown in Fig. 2 and 3.

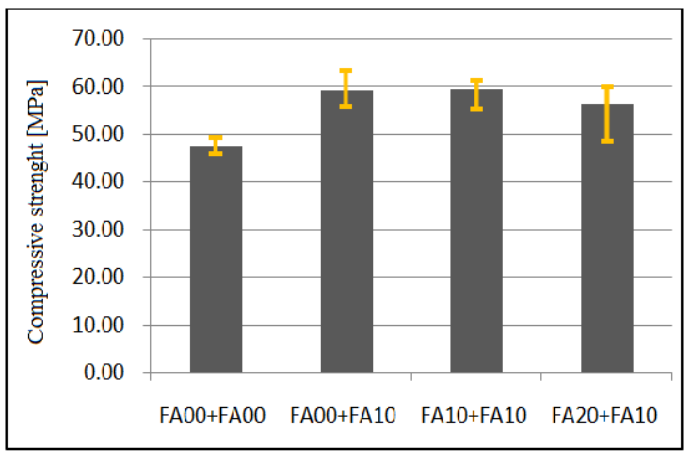

Fig. 2. Compressive strength results.

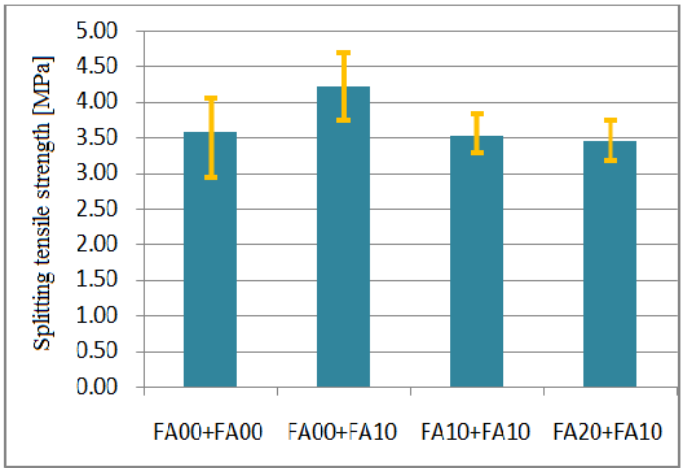

Fig. 3. Splitting tensile strength results.

The compressive strength of concrete with a different amount of additives ranges from 47.51 to $56.33 \mathrm{MPa}$. Concrete with the addition of $10 \%$ of silica fly ash and $10 \%$ of silica fume has reached a similar value as concrete without the FA addition and with only $10 \%$ of SF. The lowest compressive strength was obtained for the reference concrete (FA-00+SF-00), which was equal to $47.51 \mathrm{MPa}$. A slight reduction in compressive strength was obtained in concrete with the addition of $20 \%$ of FA and $10 \%$ of SF.

The splitting tensile strength of the concrete was also performed in the Controls Advatest9 testing machine (range $0-3,000 \mathrm{kN}$ ). A positioning frame was used to test cubic samples with a side of $150 \mathrm{~mm}$.

The highest value was obtained for concrete with a $10 \%$ SF addition. The use of $10 \%$ of FA and $10 \%$ of SF in the mix caused the concrete to reach tensile strength values close to the reference concrete after 28 days of maturation.

\subsection{Water absorption}

Testing the water absorption of concrete involves determining the ability of concrete to absorb water. The water absorption is determined based on the equation (1):

$$
n_{w}=\frac{G_{2}-G_{1}}{G_{1}} \cdot 100
$$

where: $\mathrm{G}_{1}$ - average mass of dry samples, [g]; $\mathrm{G}_{2}$ - average mass of water saturated samples; [g]. 
During the test, the samples were placed in a tub on pads with a thickness of approx. $10 \mathrm{~mm}$. The tub was supplemented with water at $18 \pm 2^{\circ} \mathrm{C}$ to half the samples' height. After 24 hours, water was added to a level $10 \mathrm{~mm}$ higher than the top surface of the samples. This level was maintained until the end of samples saturation. After a further 24 hours, the samples were removed from the tub, wiped from excess water and weighed with accuracy to $0.2 \%$. The saturation lasted until the next two weighings did not show any weight gain. After saturation, the mass of saturated samples was recorded, and then the samples were placed in a thermo-circulation dryer in which the temperature was about $105^{\circ} \mathrm{C}$. In the dryer, the samples were dried to a constant mass and the results were recorded. Fig. 4 shows the results of the concrete water absorbability that was achieved during the experiment. The lowest water absorption achieved concrete with a $10 \%$ of SF addition (2.86\%). The FA-10+SF-10 and FA-20+SF-10 concretes achieved slightly higher water absorption equal to $3.14 \%$ and $3.20 \%$, respectively. The reference concrete was the most absorptive and it was able to absorb water at the level of $4.18 \%$.

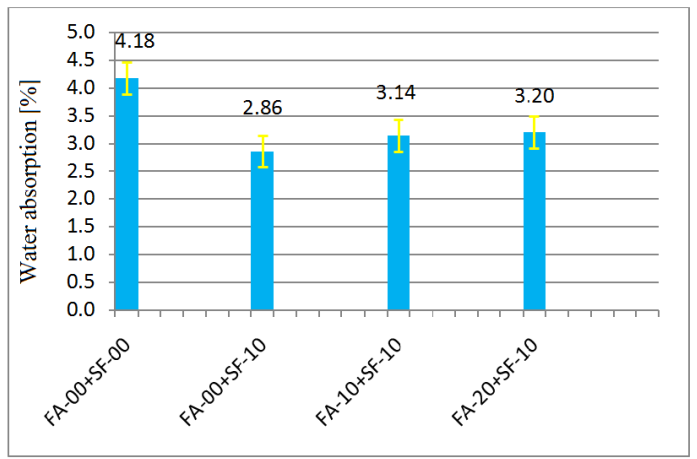

Fig. 4. Investigation results on concrete water absorption.

\subsection{Testing of the penetration depth of pressurized water}

The examination of the penetration depth of water under pressure checks the ability of concrete to resist the flow of water under hydrostatic pressure. The test consists in the impact of a stream of water at a pressure of $0.5 \mathrm{MPa}$ on a grounded sample's wall for 72 hours. For the test, cubic samples with an edge of $150 \mathrm{~mm}$ were prepared, after 28 days of maturation, 6 pieces from each mix. The samples were inserted into the test device as shown in Fig. 6, and then the pressure generation process was controlled to achieve the expected value to prevent unnecessary leakage. Fig. 5 shows the average values of the depth of penetration of pressurized water for individual mixtures. The reference concrete without additions, was characterized by the greatest penetration depth of water under pressure - an average of $22.8 \mathrm{~mm}$ deep into the sample. The penetration depth in FA-20+SF-10 concrete was similar - $22.7 \mathrm{~mm}$. The FA-10+SF-10 concrete had smaller penetration depth $-21.0 \mathrm{~mm}$. Concrete samples containing $10 \%$ of silica fume were characterized by the highest tightness compared to previous ones; water penetration depth was on average $20.7 \mathrm{~mm}$. 


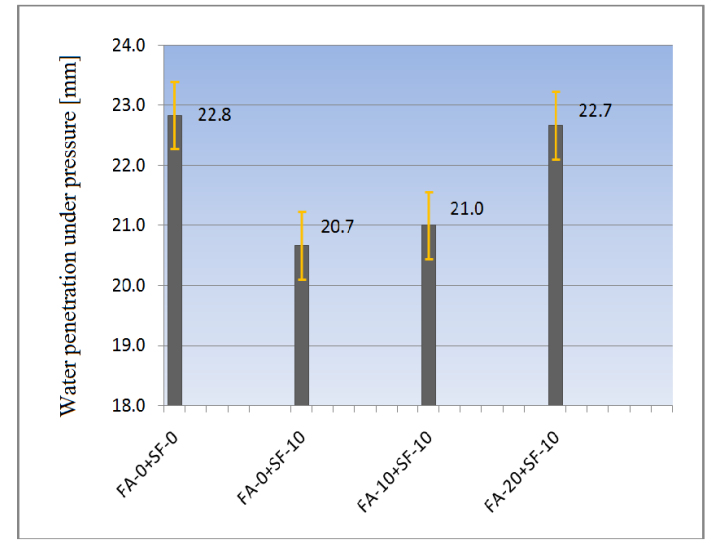

Fig. 5. Depth of water penetration under pressure.

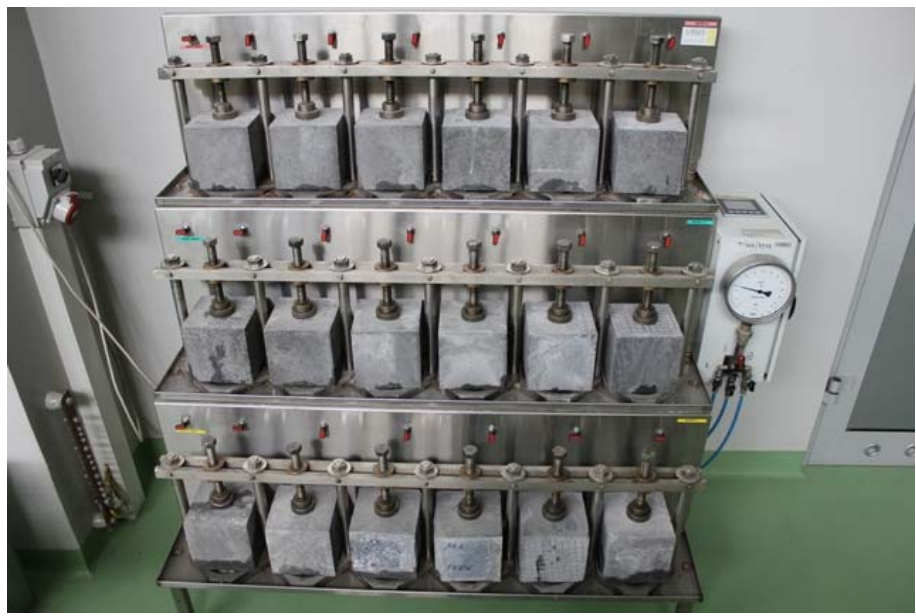

Fig. 6. Device for investigation on water penetration depth in concrete.

\subsection{Frost resistance test}

The frost resistance test was carried out on 12 cubic samples with an edge of $150 \mathrm{~mm}$, after 28 days of maturation. Samples were saturated in water for 7 days. The samples were then wiped off to remove excess moisture and weighed. Half of the samples were placed in the freezing chamber for 150 cycles ( 3 cycles per day). A single cycle consisted of freezing the sample to a temperature of $-18 \pm 2^{\circ} \mathrm{C}$ and thawing at a temperature of $18 \pm 2{ }^{\circ} \mathrm{C}$. The remaining 6 samples were placed in a container with water for further maturation. After 150 cycles, the samples were weighed and tested for compressive strength. 


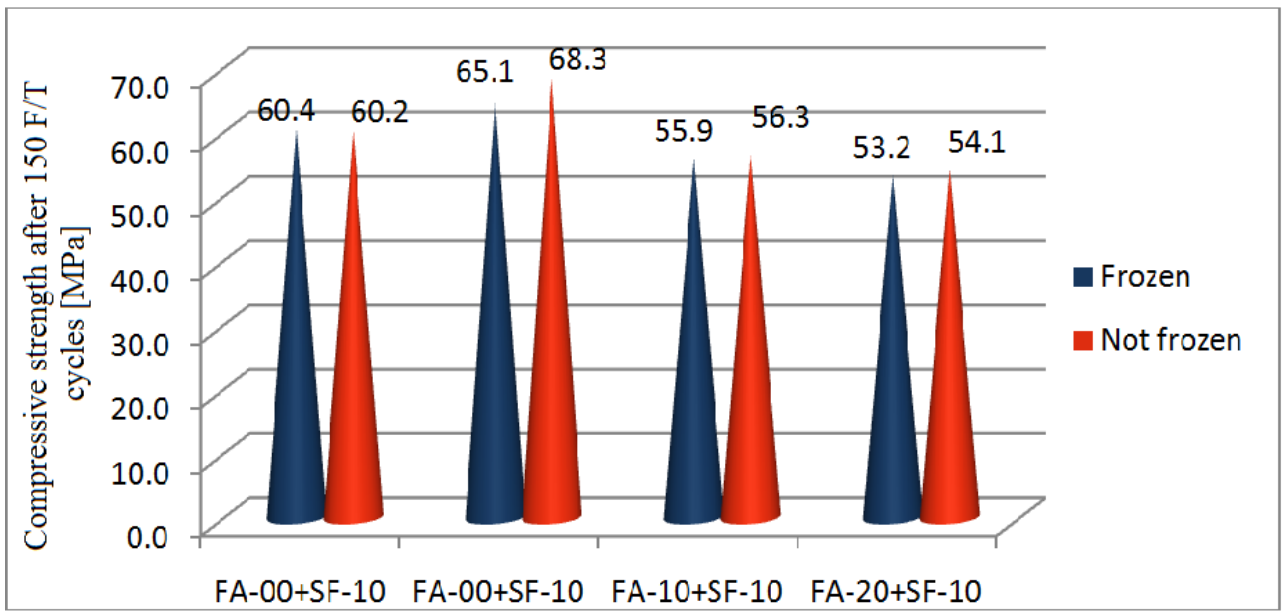

Fig. 7. Compressive strength after $150 \mathrm{~F} / \mathrm{T}$ cycles.

After the frost resistance tests, no weight loss was observed after 150 freezing and thawing cycles. The average values that were achieved during the tests are presented in Fig. 7 . The greatest decrease in the compressive strength compared to reference samples was observed for concrete with $10 \%$ of SF addition (3.2 MPa on average). In the remaining cases, the difference was without significant changes.

\section{Summary and conclusions}

Substitution of cement with siliceous fly ash and silica fume in the production of concrete results in a significant reduction of a carbon dioxide emission to the atmosphere (production of 1 ton of cement generates 1 ton of $\mathrm{CO}_{2}$ into the atmosphere); it limits the extraction of raw materials for cement production and contributes to the recycling of FA and SF.

Based on the test results obtained, it was found that the mixture with the addition of $0 \%$ of FA and $10 \%$ of SF is the most optimal and achieves the highest compressive and tensile strength as well as the lowest water absorption (at 2.86\%), and water penetration depth under hydrostatic pressure $(20.7 \mathrm{~mm})$. The decrease in compressive strength after the frost resistance test was almost $5 \%$.

Application of $10 \%$ of FA to the mixture causes slight deterioration of physical and strength parameters in relation to concrete with the SF addition only. The use of $20 \%$ of FA and $10 \%$ of SF for concrete results in deterioration of the strength parameters in relation to the reference concrete or the concrete with the SF addition only.

With the use of FA and increasing its quantity, the parameter of water absorption and the depth of penetration of pressurized water deteriorates. The compressive strength as well as the tensile strength also decreases. The least favorable results in the majority of tests were obtained by concrete without additives. When testing frost resistance, there was no drop in the compressive strength of concrete made without additives.

The use of microsilica improves the physical and mechanical parameters of the concrete. The use of $10 \%$ of FA slightly worsens its properties, but it allows to reduce the consumption of cement and proper management of the ash waste as well as to reduce the cost of making a mixture. 


\section{References}

1. P. Rathish Kumar, C. Sumanth Reddy, Md. Saleem Baig, CWB 1 (2014)

2. J. Bernal, E. Reyes, J. Massana, N. León, E. Sànchez, Const. Build. Mater. 160, 196210 (2014)

3. N. Dave, A.K. Mistra, A. Srivastava, S.K. Kaushik, Constr. Build. Mater. 107, 117-24 (2016)

4. G. Prokopski, B. Langier, Cem. Concr. Res. 30, 1427-33 (2000)

5. G. Rutkowska, M. Sobczak, Acta Scientiarum Polonorum. Technica Agraria 13, (1-2) (2014)

6. G.L. Golewski, J. Clean. Prod. 172, 218-26 (2018)

7. G.L. Golewski, Mater. Charact. 134, 335-46 (2017)

8. G.L. Golewski, Materials 10(12), 1393 (2017)

9. G.L. Golewski, Compos. Struct. 185, 105-112 (2018)

10. T. Sadowski, G.L. Golewski, Compos. Struct. 183, 527-535 (2018)

11. G. L. Golewski, J. Civ. Eng. Manag. 23(5), 613-620 (2017)

12. P. Zhang, Q.Y. Qiao-Yan Guan, T.H. Zhang, Struct. Eng. Mech. 59 (2), 261-75 (2016)

13. T. Nochaiya, W. Wongkeo, A. Chaipanich, Fuel 89, 768-774 (2010)

14. L. Marsavina, F. Berto, R. Negro, D.A. Serban, E. Linul, Theor. Appl. Fract. Mech. 91, 148-154 (2017)

15. P. Niewiadomski, J. Hola, A. Cwirzen, Arch. Civ. Mech. Eng. 18, 877-886 (2018)

16. P. Lukowski, Materials 9, 839 (2016)

17. Z. Giergiczny, A. Król, J. Hazard. Mater. 160, 247-255 (2008)

18. C. Belviso, Prog. Energy Combust. Sci. 65, 109-135 (2018)

19. Ch.S. Kankariya, H. S. Patil, S. Bhamre, M. D. Mhasde, International journal of recent trends in engineering: IJRTE 03(05), 562-565 (2017)

20. M. Alwaeli, Radiat. Phys. Chem. 83, 54-60 (2013)

21. V. M. Malhotra, V.S. Ramachandran, R.F. Feldman, P.C. Aitcin, CRC Press, Inc. (1987)

22. ASTM C 618-03 Standard specification for coal fly ash and raw or calcined natural pozzolan for use in concrete 